\title{
Characterizing void ratio and compressibility of Holocene peat with CPT for assessing coastal-deltaic subsidence
}

\author{
Kay Koster1,2*, Ger De Lange ${ }^{3}$, Ronald Harting ${ }^{2}$, Eppie de Heer ${ }^{2}$ \& Hans Middelkoop ${ }^{1}$ \\ ${ }^{1}$ Faculty of Geosciences, Department of Physical Geography, Utrecht University, Heidelberglaan 2, Utrecht 3584 CS, the \\ Netherlands \\ 2 TNO - Geological Survey of the Netherlands, Princetonlaan 6, Utrecht, 3584 CB, the Netherlands \\ ${ }^{3}$ Deltares, Department of Groundwater and Subsurface Systems, Princetonlaan 6, Utrecht 3584 CB, the Netherlands \\ (iD K.K., 0000-0001-5321-1934; R.H., 0000-0002-7228-3375; H.M., 0000-0002-9549-292X \\ *Correspondence: kay.koster@tno.nl
}

\begin{abstract}
Cone penetration testing (CPT) was used to determine the void ratio and compressibility of Holocene peat present in the coastal-deltaic plain of the Netherlands, to explore its application for mapping the subsidence potential of this low-lying area. CPT sounds the mechanical behaviour of subsurface layers when penetrated with a cone, and is the most widely used site investigation method in the Netherlands. In this study 41 peat layers in the coastal-deltaic plain were sounded, and subsequently cored for determination of peat type, organic matter content, degree of decomposition and void ratio. The results revealed that cone resistance depends on the void ratio of the peat layer. The compression parameters coefficient of volume compressibility $\left(m_{\mathrm{v}}\right)$ and compression index $\left(C_{\mathrm{c}}\right)$ were derived from this. The results further revealed that the compressibility of the peat increases with increasing organic matter content. It is concluded that for mapping the susceptibility of the coastal-deltaic plain to future subsidence by peat compression, CPT has the potential to become a useful tool, as thousands of CPTs are conducted in the Netherlands each year, and their logged measurements are stored in a freely accessible national database.
\end{abstract}

Received 2 October 2017; revised 15 November 2017; accepted 27 November 2017

Land subsidence caused by the compression and oxidation of Holocene peat is threatening the viability of many urbanized lowlying coastal-deltaic plains (Serva \& Brunamonte 2007; Törnqvist et al. 2008; Drexler et al. 2009; Van Asselen 2011). The mechanically weak organic composition of peat and its high quantity of porewater make it very susceptible to compression when vertical stress increases by surface loading or phreatic groundwater level lowering. This results in severe volumetric loss, as excess porewater is expelled and the peat densifies (Den Haan 1992; Den Haan \& Kruse 2006; Mesri \& Ajlouni 2007). Oxidation of peat owing to groundwater level lowering causes further subsidence by deterioration of organic matter during periods of aeration (Drexler et al. 2009).

Peat is abundantly present within the Holocene coastal-deltaic subsurface of the Netherlands. It formed between $c .9000$ and 1000 years BP, and at present occurs intercalated with the clastic fluvial and coastal deposits of the Holocene sequence (Hijma et al. 2009). During the previous millennium, this peat experienced severe volumetric loss over vast areas, owing to artificial drainage for agricultural practices, causing the peat to compress and oxidize (Schothorst 1977). Furthermore, additional overburden and peat mining locally amplified the subsidence (Erkens et al. 2016). Consequently, c. $50 \%$ of the surface area of the Holocene coastaldeltaic plain is at present situated below mean sea level (Fig. 1). Although c. $20 \mathrm{~km}^{3}$ of Holocene peat has already disappeared as a result of human activities (Erkens et al. 2016), over $15 \mathrm{~km}^{3}$ is still embedded in the coastal-deltaic plain (TNO-GSN 2016). Present rates of subsidence in areas with Holocene peat in the subsurface range between 1 and $12 \mathrm{~mm} \mathrm{a}^{-1}$ (Nieuwenhuis \& Schokking 1997; Van den Born et al. 2016), of which c. $35 \%$ is attributed to peat compression and c. $65 \%$ to oxidation (Schothorst 1977). As phreatic groundwater levels are progressively being lowered, and overburden is systematically increased to facilitate agriculture and urbanization (Van den Born et al. 2016), the coastal-deltaic plain of the
Netherlands remains highly vulnerable to future subsidence, and the resulting increase in flood risk, damage to (sub-)surface infrastructure and loss of agricultural fields by salinization.

A physical property of peat that determines its potential for subsidence is the void ratio (e), which expresses the ratio between non-solid and solid components of a subsurface layer (CUR 1992). When vertical effective stress $\left(\sigma_{\mathrm{v}}^{\prime}\right)$ increases, the solid particles of peat are packed tighter together as excess porewater is expelled and the void ratio decreases. This process is referred to as primary compression. The thickness reduction of subsurface peat layers resulting from primary compression is reflected at the surface as subsidence, which has often been documented in the coastal-deltaic plain of the Netherlands (Muntendam-Bos et al. 2009; Ngan-Tillard et al. 2010). To express decreasing void ratio by increasing vertical effective stress, two parameters are commonly used that serve as input for primary compression calculations (Jorgensen 1980), as follows. (1) The coefficient of volume compressibility $\left(m_{\mathrm{v}}\right)$ expresses decreasing void ratio for increments of increasing vertical effective stress (equation (1)). The $m_{\mathrm{v}}$ of soil reduces with increasing load increments, and consequently deeply buried peat layers have a lower $m_{\mathrm{v}}$ (or compressibility) than shallow situated peat. This causes the subsidence contribution of surficial peat beds by compression to be higher than that of deeper situated peat when vertical effective stress is uniformly increased. (2) The compression index $\left(C_{\mathrm{c}}\right)$ expresses the decrease in void ratio versus the logarithm of increasing vertical effective stress (equation (2)). In a plot, this produces a (near) straight line, and consequently $C_{\mathrm{c}}$ is considered a constant that does not change for a peat bed when it becomes buried deeper within the coastal-deltaic plain.

$$
m_{\mathrm{v}}=\frac{\Delta e / \Delta \sigma_{\mathrm{v}}^{\prime}}{1+e}
$$




\section{K. Koster et al.}

$$
C_{\mathrm{c}}=\frac{\Delta e}{\log \left(\left(\sigma_{\mathrm{v}}^{\prime}+\Delta \sigma_{\mathrm{v}}^{\prime}\right) / \sigma_{\mathrm{v}}^{\prime}\right)}
$$

where $m_{\mathrm{v}}$ is coefficient of volume compressibility $\left(\mathrm{kPa}^{-1}\right), e$ is void ratio $(-), \Delta e$ is increase in void ratio $(-), \Delta \sigma_{\mathrm{v}}^{\prime}$ is increase in vertical effective stress $(\mathrm{kPa}), C_{\mathrm{c}}$ is compression index (-) and $\sigma_{\mathrm{v}}^{\prime}$ is vertical effective stress $(\mathrm{kPa})$.

The $m_{\mathrm{v}}$ and $C_{\mathrm{c}}$ compression parameters are often used as input for primary compression functions used in large-scale land subsidence mapping in the Netherlands (Van der Meulen et al. 2007; Muntendam-Bos et al. 2009; Fokker et al. 2015). However, these studies use standard soil type dependent compression parameter values for Holocene peat, as large-scale information on the void ratio of peat beds and their compressibility is lacking. Because of spatiotemporal differences in peat-forming environments, and postdepositional loading and drainage, the void ratio of peat will vary laterally and vertically throughout the Holocene sequence. In particular, the differences in compressibility between shallow and deeper situated peat are not revealed using single parameter values. Therefore, because of the severity of coastal-deltaic subsidence, new approaches need to be explored to map the void ratio of peat to eventually produce improved subsidence maps.

The coastal-deltaic plain of the Netherlands has a surface area of c. $17000 \mathrm{~km}^{2}$, and mapping the void ratio of the peat beds would require extensive datasets. Such datasets do not exist at present, and acquiring new data on this spatial scale is expensive and time consuming. Consequently, alternative approaches are explored. Several studies have shown that the compressibility of unconsolidated subsurface layers is determinable with cone penetration testing (CPT) (Sanglerat 1972; CUR 1992; Lunne et al. 1997; Koster et al. 2016). In the international field of site investigation, CPT is among the most popular methods to sound the mechanical properties of the subsurface. Furthermore, its operational procedures are internationally standardized, and therefore relations between CPT and soil compressibility are applied worldwide (Lunne et al. 1997). Internationally, standard soil type dependent parameter values are used to determine soil compressibility by CPT, regardless of the geographical or stratigraphical position of the subsurface layers, their age, burial history, etc. Therefore, these international standard values are not necessarily applicable for Holocene peat embedded in the coastal-deltaic plain of the Netherlands, and need to be adjusted prior to application for subsidence mapping.

An advancement of CPT is that its log data are digitally stored in databases. In the Netherlands, for instance, $>100000$ CPT logs are contained in a national database (TNO-GSN 2016). The CPT logs from this database might contribute to future geomechanical characterization of peat embedded in the coastal plain of the Netherlands, which for this area eventually could overcome the data sparsity regarding void ratio mapping. However, before this database can be applied for this purpose, studies focusing on CPT measurements and physical peat properties should be conducted to determine the feasibility of such an approach.

In this study, an empirically derived relation between CPT and void ratio of peat layers embedded in the coastal plain of the Netherlands is presented. Peat layers of heterogeneous composition were investigated, obtained from various depths throughout the entire Holocene coastal zone of the Netherlands. The examined peat layers are in permanent waterlogged conditions, and have therefore not experienced thickness reduction by oxidation. The main objectives of this study were (1) to quantitatively estimate the void ratio and derived compressibility of Holocene peat based on its mechanical behaviour detectable with CPT, and (2) to evaluate the potential of CPT for the mapping of the compressibility of peat for land subsidence assessments.

\section{Heterogeneous composition of Holocene peat}

The composition of the peat embedded in the Holocene sequence of the Netherlands is very heterogeneous. Causes of this heterogeneity have been well documented, and include trophic conditions during peat formation and amount of admixed mineral material (Pons 1992; Bos et al. 2012). Eutrophic conditions allow the development of typical peat-forming species such as reed and wood. Such conditions are found adjacent to rivers, and even in slightly brackish environments such as lagoons and estuaries. Flowing water in these nutrient-rich environments carries clastic material in suspension, which, during periods of high water, is transported into the wetlands. Owing to settling, the amount of clastic components within peat decreases away from the source towards the distal parts of a wetland; as a result, eutrophic peat often contains fine clastic components. Peat formed under mesotrophic conditions, in environments distal to eutrophic systems or fed by seepage water, is often composed of sedge remains. Because of the larger distance from a clay-transporting source, this peat is generally poor in mineral constituents. Where peat accumulates above the regional groundwater level, it receives water only by precipitation; under these nutrient-poor conditions oligotrophic peat forms, which is typically composed of mosses or heather, and barely contains clastic admixture. Both during and after peat formation, the organic components of peat decompose when exposed to air, causing the peat material to become amorphous. Under natural conditions this may occur as a result of seasonally low groundwater levels causing aeration of the top layer of the peat; artificial drainage and groundwater lowering has resulted in large-scale decay of peat in recent decades to centuries. As a consequence, together with peat type and clastic admixture, the degree of decomposition is another factor that determines the heterogeneity of peat composition.

\section{Data and methods}

To correlate CPT measurements to void ratio of peat, 41 peat layers embedded in the coastal-deltaic plain of the Netherlands were investigated. These peat layers were sampled from mechanically collected cores and in situ sounded by CPT (Fig. 1). In total 26 locations were investigated; at 15 locations multiple peat layers were encountered. The dataset was initially collected as part of a national geological subsurface mapping programme conducted by the Geological Survey of the Netherlands (TNO-GSN). The coupled CPT and borehole logs used in this study were collected between 2006 and 2013, and their site locations were selected to obtain a maximum variation in geological formations. The lateral distances between the locations of the CPT and boreholes were minimized where possible, and range between $<1-10 \mathrm{~m}$ (34 locations) and 10$19 \mathrm{~m}$ (seven locations).

The sediment and organic material contained in the cores were described and analysed in the laboratory of TNO-GSN. For 37 of the encountered peat layers, the dominant peat-forming vegetation was determined, and the degree of decomposition for 15 layers. The degree of decomposition was described using the TNO-GSN standard, which is based on the Von Post scale (e.g. Long \& Boylan 2012), but distinguishes three classes (see Bosch 2000: standard protocol TNO-GSN). For all peat layers, organic matter content was determined by thermogravimetric analysis. Standard procedures were followed to measure vertical effective stress and the void ratio of the peat layer (NEN 5110, standard protocol for the Netherlands; NEN (2001)).

Conventionally, compression parameters of peat are determined for samples subjected to laboratory compression testing. In this study, however, the dataset comprises peat samples from layers situated at different depths with a heterogeneous composition. Therefore, to validate the use of a heterogeneous dataset, 


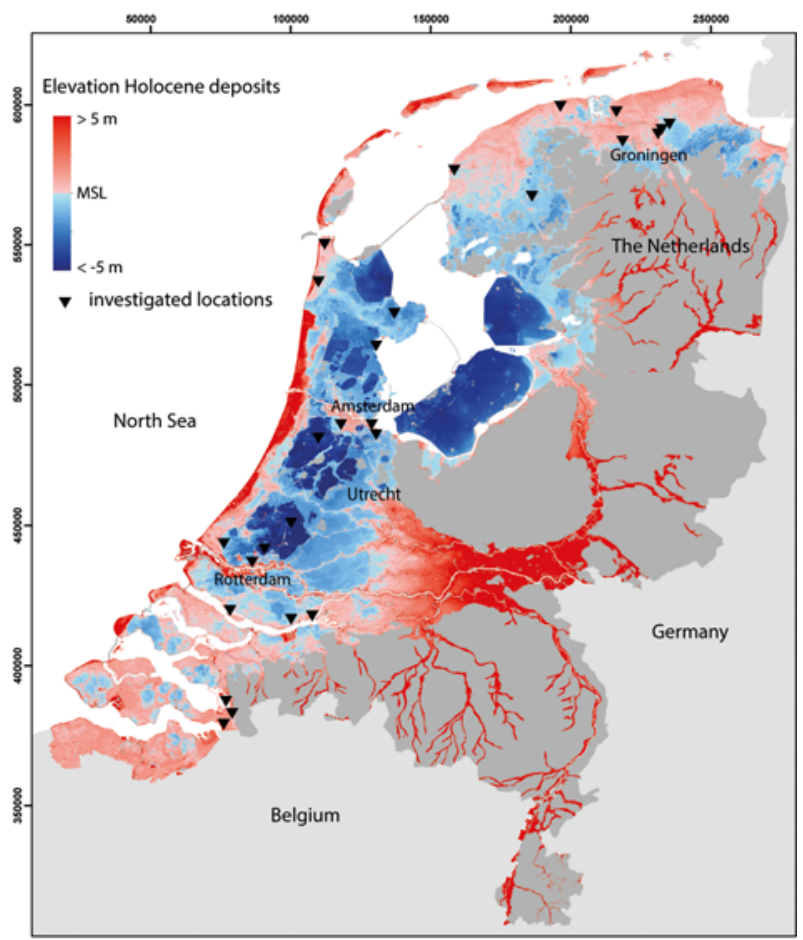

Fig. 1. A digital elevation model representing the surface elevation of the top of the Holocene coastal plain of the Netherlands (TNO-GSN 2016). The blue zone indicates land situated below mean sea level (MSL), and represents c. $50 \%$ of the surface area of the entire coastal plain, or c. $25 \%$ of the entire country. The black triangles indicate the locations of the coupled CPT-mechanically cored boreholes used in this study.

correlations were determined between decreasing void ratio and increasing effective stress. From laboratory compression testing it has long been acknowledged that the relation between void ratio and vertical effective stress is best described by using a power function (Den Haan 1994). To determine whether this also accounts for this dataset, similar functions were fitted on the sample data. From this, the $m_{\mathrm{v}}$ (load increments of $20 \mathrm{kPa}$ ), and $C_{\mathrm{c}}$ (stress range of 10$120 \mathrm{kPa}$ ) were calculated. From laboratory compression testing it is also known that peat with various composition shows differential compression behaviour. Den Haan (1992) determined that peat enriched in sediment has lower initial void ratios than highly organic peat, and consequently is less compressible. Den Haan (1992) also found that peat-forming vegetation influences compressibility. Wood peat, for instance, has a denser matrix as it is composed of, besides branches and stems, very fine organic matter constituents, whereas reed peat is composed of relatively large organic fibres. This makes reed peat more compressible than wood peat. Furthermore, decomposition of the organic matter of peat reduces its compressibility, as it loses its fibrous structure and small particles occupy the pore space (O'Kelly \& Pichan 2013). To assess the influence of the heterogenous composition of the dataset on the obtained relations between void ratio and vertical effective stress, and subsequently for CPT measurements, the results were further categorized based on organic matter content, peat-forming vegetation and degree of decomposition. Organic matter classes were set at $<40 \%, 40-60 \%$, $60-80 \%$ and $>80 \%$, peat-forming vegetation was categorized into reed, wood and heather, and the degree of decomposition into three classes, AV1 slightly decomposed, AV2 moderately decomposed and AV3 severely decomposed.

\section{CPT analyses}

A CPT measures in situ mechanical soil behaviour by pushing a cone attached to a series of rods into the subsurface at a constant rate

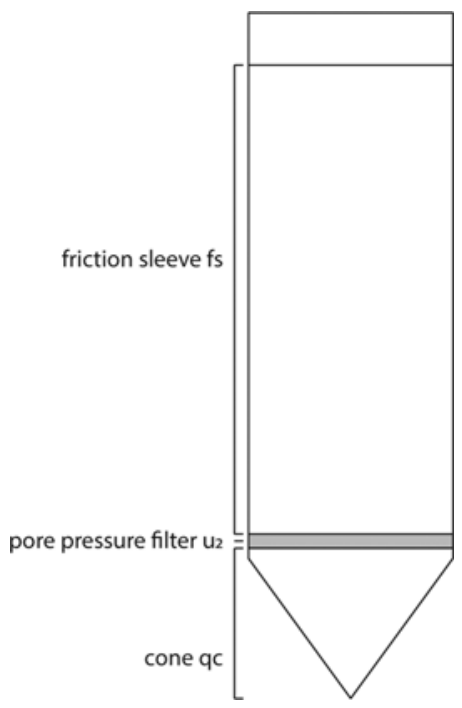

Fig. 2. Schematic representation of a CPT cone showing the location of the porewater pressure filter $\mathrm{u}_{2}$, the tip that measures cone resistance $\left(q_{\mathrm{c}}\right)$ and the sleeve measuring sleeve friction $\left(f_{\mathrm{s}}\right)$ (after Lunne et al. 1997).

of $20 \pm 5 \mathrm{~mm} \mathrm{~s}^{-1}$, and sounds with a vertical resolution of $20 \mathrm{~mm}$ (Lunne et al. 1997; ISO 2005). The cone used was standard sized, with a tip surface area of $15 \mathrm{~cm}^{2}$, a sleeve area of $20 \mathrm{~cm}^{2}$ and an apex of $60^{\circ}$. The CPT cone used measures cone resistance $q_{\mathrm{c}}$, sleeve friction $f_{\mathrm{s}}$ and porewater pressure at a filter located at $u_{2}$ (Fig. 2). The cone had a net area ratio of 0.59 , which was used to correct $q_{\mathrm{c}}$ for unequal porewater effects, to give corrected cone resistance $q_{\mathrm{t}}$ (equation (3)). To obtain net cone resistance $q_{\mathrm{n}}$, total vertical stress exerted by the deposits overlying the peat layer was subtracted from $q_{\mathrm{t}}$ (equation (4)). The CPT measurements were executed with a cone resistance precision of $100 \mathrm{kPa}$ (see ISO 2005).

$$
\begin{gathered}
q_{\mathrm{t}}=q_{\mathrm{c}}+u_{2}\left(1-a_{\mathrm{n}}\right) \\
q_{\mathrm{n}}=q_{\mathrm{t}}-\sigma_{\mathrm{v}}
\end{gathered}
$$

where $q_{\mathrm{c}}$ is cone resistance (MPa), $q_{\mathrm{t}}$ is corrected cone resistance (MPa), $q_{\mathrm{n}}$ is net cone resistance (MPa), $u_{2}$ is porewater pressure behind the cone tip (MPa), $a_{\mathrm{n}}$ is net area ratio (-) and $\sigma_{\mathrm{v}}$ is total vertical stress $(\mathrm{MPa})$.

Compression increases the stiffness and strength of peat, as the fibres are packing increasingly tighter together and interlock. In the Netherlands, it has been observed that cone resistance increases with deeper burial of Holocene peat owing to increasing compression (Cheng-hou et al. 1990; Koster et al. 2016). Previously published empirical relations between soil compressibility and CPT measurements use this increase in cone resistance to express the compression of sounded layers. To parametrize these relations for Holocene peat in the coastal-deltaic plain of the Netherlands, a simple regression analysis was performed between the void ratios measured in the laboratory and the $q_{\mathrm{n}}$ derived from the CPT logs. To test the influence of heterogeneous peat composition on net cone resistance, the peat samples were categorized in the same organic matter, peat type and degree of decomposition classes.

\section{Results}

The relation between void ratio and vertical effective stress shows that void ratios decrease in peat samples from layers that have been exposed to increasing vertical effective stress (Fig. 3a). A power function was fitted yielding $r^{2}=0.54$ (equation (5)) (see Den Haan 


\section{K. Koster et al.}

(a)

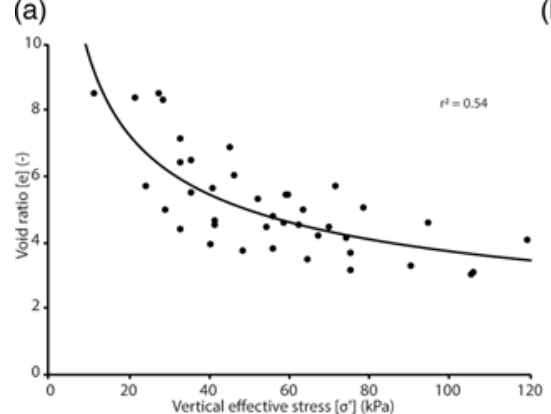

(b)

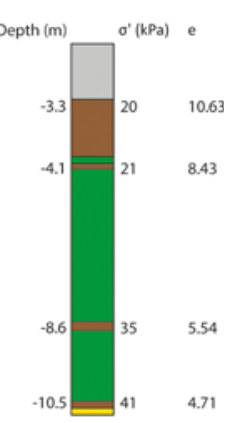

Fig. 3. (a) Relation between void ratio and vertical effective stress. (b) Lithological composition of the Holocene coastal sequence encountered in a core: brown, peat; green, coastal clay; yellow, Pleistocene aeolian sands; grey, brought-up anthropogenic soil. The associated effective stress $\left(\sigma_{\mathrm{v}}^{\prime}\right)$, and void ratio $(e)$ of the peat layers are indicated. The void ratio decreases with increasing vertical effective stress.

1992). This relation shows that peat loses most of its volume under the initial increase in vertical effective stress, with the expulsion of large quantities of porewater, whereas subsequent compression requires increasingly larger stresses because of the tightening of the fibres. At vertical effective stress higher than $c .2000 \mathrm{kPa}$ the void ratio of peat is less than unity, indicating that the volume of a peat is dominated by solid components. These vertical effective stresses are, however, not prevalent within the Holocene sequence of the Netherlands, as values here are $>200 \mathrm{kPa}$ (TNO-GSN 2016). In Figure $3 \mathrm{~b}$, the relation between increasing vertical effective stress and decreasing void ratio is exemplified for one of the sampled cores. This schematic representation shows that deeper situated peat progressively had become denser owing to the weight of the overburden.

$$
e=a \sigma_{\mathrm{v}}^{\prime-b}
$$

where $e$ is void ratio $(-), \sigma_{\mathrm{v}}^{\prime}$ is vertical effective stress $(\mathrm{kPa}), a=25.1$ and $b=0.413$.

The laboratory measurements show that void ratios of peat subjected to the lowest measured effective stress $(10 \mathrm{kPa})$ are of the order of 5-8.5 (Fig. 3a). According to Mesri \& Ajlouni (2007), uncompressed surficial peats typically have void ratios ranging between 7.5 and 30 . The relative low void ratios of the near-surface peat layers embedded in the coastal-deltaic plain reflect the thousand-year history of human-induced vertical stress changes by drainage and loading of the peat, and creep processes. According to Landva (2006), pristine freshly formed peat beds in conditions with a water depth of $1 \mathrm{~m}$ experience a vertical effective stress of $3.7 \mathrm{kPa}$. When extrapolating the regression of Figure $3 \mathrm{a}$ to $3.7 \mathrm{kPa}$, a void ratio of 14.6 is obtained. This would have been the initial void ratio of the peat, and corresponds well to the typical values presented by Mesri \& Ajlouni (2007).

Den Haan (1992) published an overview of 38 laboratory compression tests on single Holocene peat samples deriving from various different areas throughout the coastal-deltaic plain of the Netherlands. The regression presented in Figure 3a was compared with this overview, to validate the obtained trend with these representative compression test results. Den Haan (1992) used the specific volume of peat $(1+e)$ rather than its void ratio, and therefore the void ratios measured in this study were expressed as specific volume. A representative selection was made of the test results published by Den Haan (1992), to adequately place the results of this study into context (Fig. 4). The trend obtained in this study shows good overlap with the vertical effective stress-specific volume relations of Den Haan (1992).

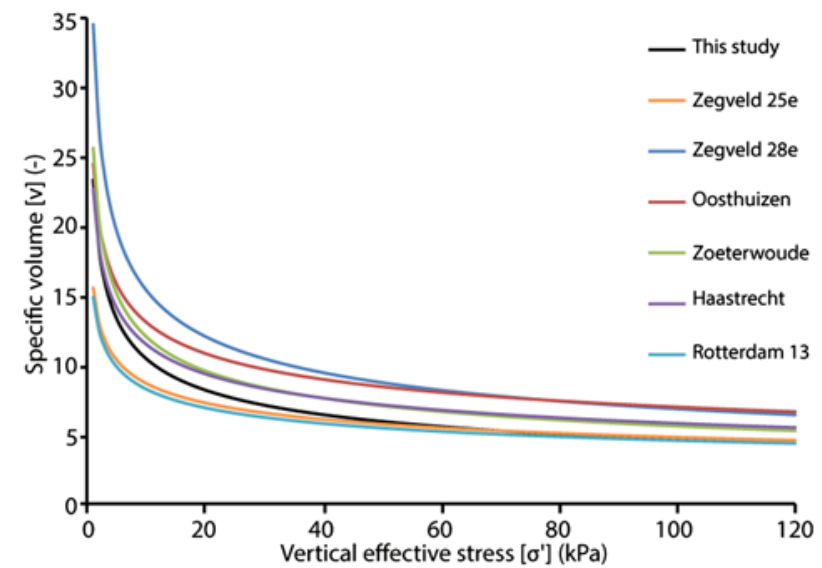

Fig. 4. The vertical effective stress-void ratio trend fitted on the dataset used in this study corresponds well to representative compression test results of Den Haan (1992).

In Figure 5a, void ratios are plotted against the vertical effective stress that produced them, with the samples subdivided into different organic matter classes. New power functions were fitted, which yielded $r^{2}$ ranging between 0.24 for peat with $<40 \%$ organic matter and 0.62 for peat with $60-80 \%$ organic matter. A pattern emerged indicating that void ratio increases with organic matter content. Den Haan (1992) determined ranges of the $a$ and $b$ parameters of equation (5) to express compressibility based on differential organic matter contents. These were determined for the specific volume $(1+e)$ of peat. In Figure $5 b$, these ranges of $a$ and $b$ parameters are indicated with dashed lines. The $a$ and $b$ parameters obtained in this study for the different organic matter classes were determined for specific volume as well, and then compared with these ranges. This revealed that the $a$ parameter corresponds to the lower bound of Den Haan (1992), whereas the $b$ parameter, especially for organic matter contents $<40 \%$, plots below the lower bound. Nevertheless, linear trends fitted through the four organic matter classes provide good correlations that reflect the decreasing compressibility of peat with increasing sediment admixed in the peat. These linear trends were used in equation (5) to produce relations between decreasing void ratio (equation (6)) or specific volume (equation (7)) and increasing effective stress for peat with different organic matter contents (see Den Haan 1992):

$$
\begin{gathered}
e=(2.27+27.55 N) \sigma_{\mathrm{v}}^{\prime-(0.12+0.34 N)} \\
v=(3.81+23.79 N) \sigma_{\mathrm{v}}^{\prime-(0.09+0.29 N)}
\end{gathered}
$$

where $e$ is void ratio (-), $N$ is organic matter content $(-), \sigma_{\mathrm{v}}^{\prime}$ is vertical effective stress $(\mathrm{kPa})$ and $v$ is specific volume $(1+e)(-)$.

The $m_{\mathrm{v}}$ determination resulted in a maximum $m_{\mathrm{v}}$ of $0.0165 \mathrm{kPa}$ at low vertical effective stress $\left(\sigma_{\mathrm{v}}^{\prime}\right.$ of $\left.10-30 \mathrm{kPa}\right)$ that decreased to a minimum of $0.0032 \mathrm{kPa}$ for increasing vertical effective stress $\left(\sigma_{\mathrm{v}}^{\prime}\right.$ of 90-110 kPa) (Fig. 6). $C_{\mathrm{c}}$ yielded a value of 5.8. $m_{\mathrm{v}}$ and $C_{\mathrm{c}}$ were also determined for the different organic matter classes using the functions displayed in Figure 5a. This revealed that $m_{\mathrm{v}}$ and $C_{\mathrm{c}}$, and hence the compressibility of peat, increase with increasing organic matter content. Linear regression functions were used to describe the relations between $m_{\mathrm{v}}$ and $C_{\mathrm{c}}$ and peat organic matter content (Fig. 7).

The categorization on vegetation type and degree of decomposition showed that reed peat is slightly more compressible than wood peat, and moderately decomposed peat (AV2) is slightly more compressible than severely decomposed peat (AV3) (Fig. 8a and b). $m_{\mathrm{v}}$ for reed peat ranges between 0.0143 and $0.0027 \mathrm{kPa}$, and for wood peat between 0.0166 and $0.0032 \mathrm{kPa}$, whereas $m_{\mathrm{v}}$ for AV2 
(a)

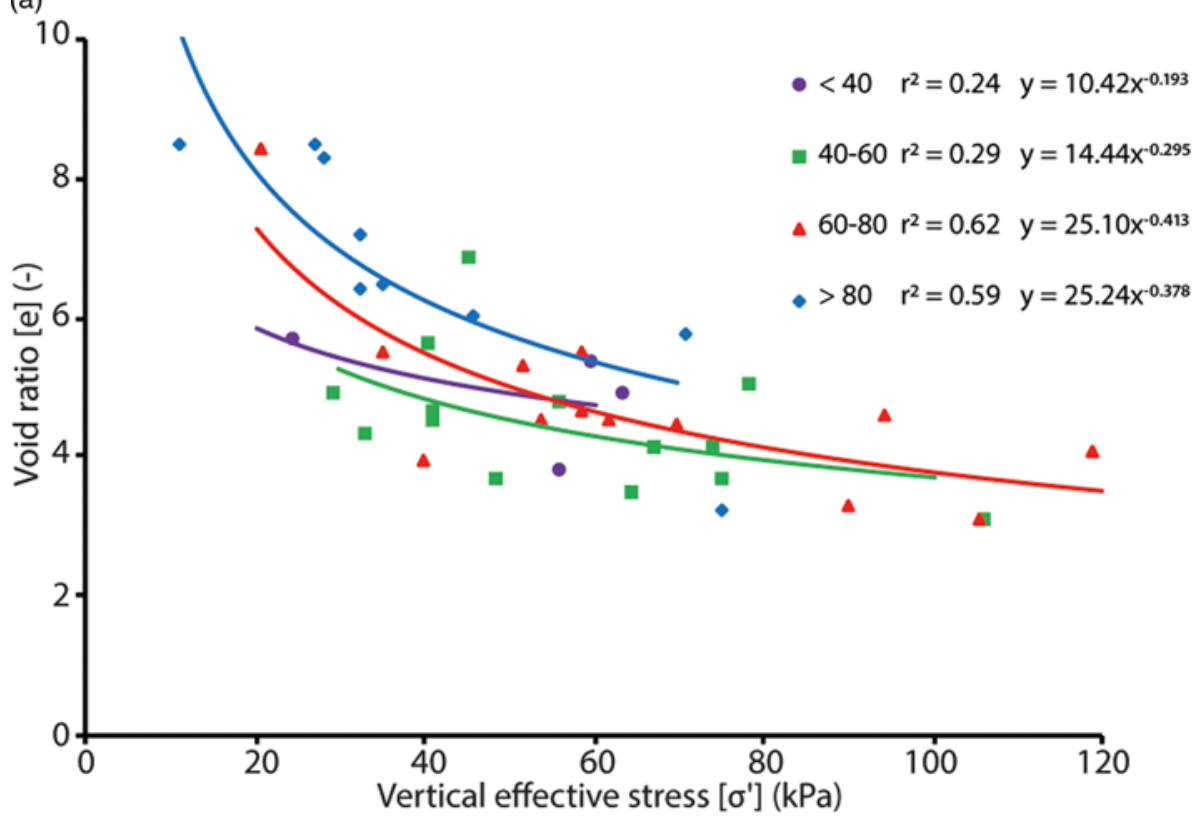

(b)
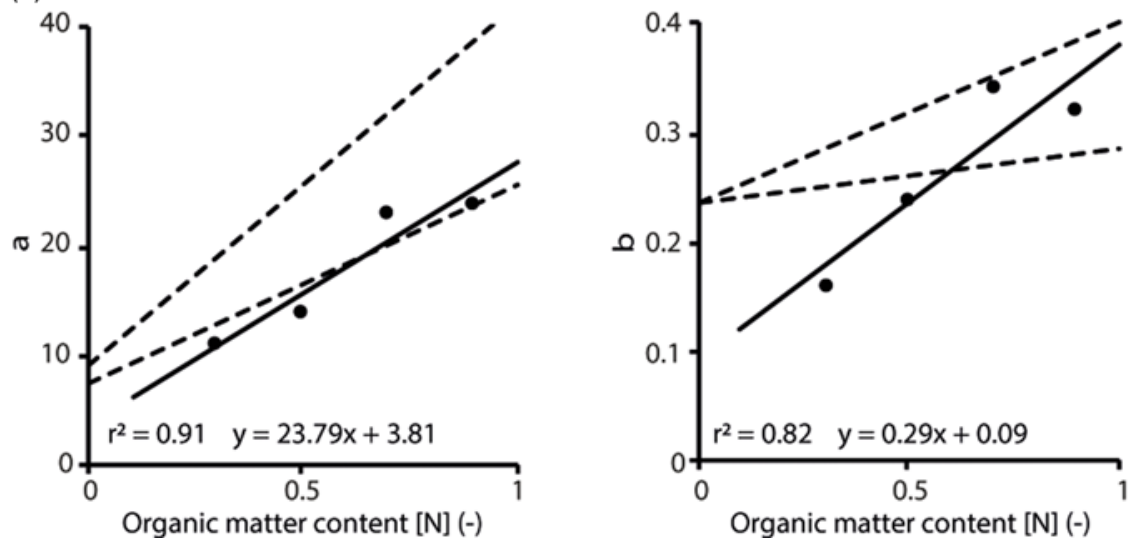

Fig. 5. (a) Overview of the different trend functions for the organic matter classes. (b) Linear relations were obtained between the $a$ and $b$ parameters of the different fits. The dashed lines indicate the ranges for typical a (top) and b (bottom) values of peat (Den Haan 1992). ranges between 0.0229 and $0.0046 \mathrm{kPa}$, and for AV3 between 0.0132 and $0.0025 \mathrm{kPa}$. $C_{\mathrm{c}}$ for reed and wood peat is 4.7 and 5.5 respectively, $C_{\mathrm{c}}$ for AV2 is 11.0, and for AV3 it is 4.3.

\section{$C P T$}

The obtained relation between net cone resistance and void ratio confirms previously made observations that generally lower void ratios occur in peat layers where net cone resistance was higher

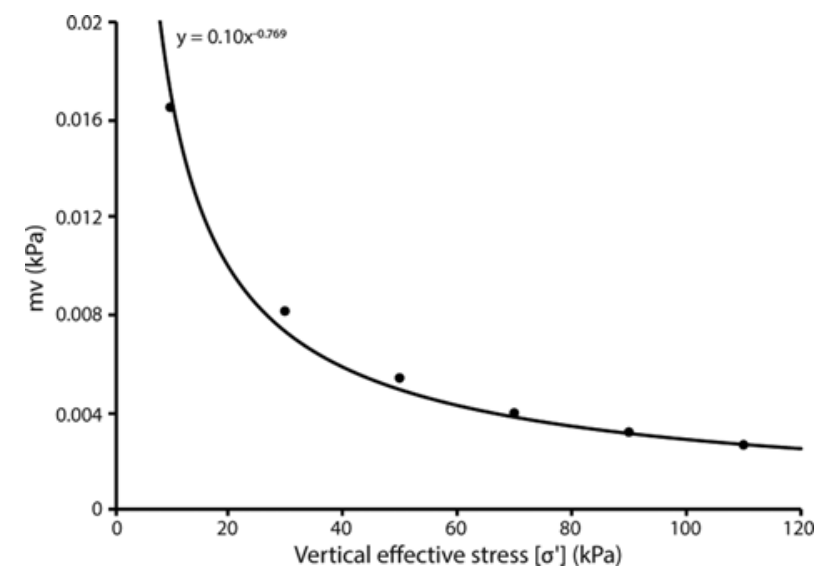

Fig. 6. The relation between the coefficient of volume compressibility $\left(m_{\mathrm{v}}\right)$ and vertical effective stress $\left(\sigma^{\prime}\right)$ for the selected stress intervals.
(Fig. 9a) (Cheng-hou et al. 1990; Koster et al. 2016). This relation was best described by a power function $\left(r^{2}=0.65\right)$ (equation (8)). In Figure $9 \mathrm{~b}$, it is shown that increasing net cone resistance linearly correlates to increasing vertical effective stress exerted on the peat. This was previously also observed for Holocene peat by Den Haan \& Kruse (2006) and Koster et al. (2016), and is critical in relating net cone resistance to void ratio and subsequently compressibility, as this justifies its substitution for vertical effective stress:

$$
e=\alpha q_{\mathrm{n}}^{-\beta}
$$

where $\alpha=4.22$ and $\beta=0.481$.

The four organic matter classes reveal similar trends between vertical effective stress and void ratio. Figure 10a shows that $q_{\mathrm{n}}$ of organic-rich peat has a higher void ratio compared with peat beds poor in organic matter. This especially accounts for peat that contains more than $80 \%$ organic matter. The $r^{2}$ values are substantially higher than those obtained for the relation between void ratio and vertical effective stress per organic matter class, and range between 0.67 and 0.78 . Similar to vertical effective stress and void ratio relations, linear trends between the parameters of equation (8) were established for the different organic matter content classes (equation (9)) (Fig. 10b):

$$
e=(3.64+0.86 N) q_{\mathrm{n}}^{-(0.28+0.33 N)}
$$

where $e$ is void ratio (-), $N$ is organic matter content $(-)$ and $q_{\mathrm{n}}$ is net cone resistance $(\mathrm{MPa})$. 
(a)

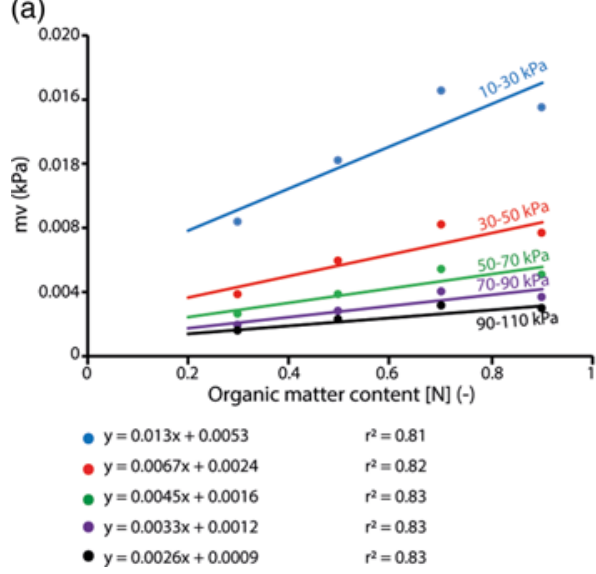

(b)

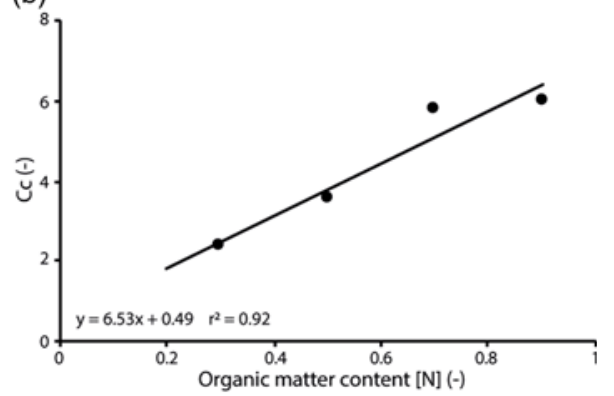

Fig. 7. Plots showing increasing compressibility of peat with increasing organic matter content: (a) the coefficient of volume compressibility $\left(m_{\mathrm{v}}\right)$ for different stress increments; (b) the compression index $\left(C_{\mathrm{c}}\right)$.
In Figure 11, the relationships between void ratio and cone resistance for the different vegetation types and degree of decomposition are shown. The fitted trend lines intersect and, consequently, the previously observed differential compressibility between peat types and degree of decomposition (Fig. 8) is not reflected in the CPT measurements.

Critical in applying CPTs for subsidence assessments is using cone resistance to estimate $m_{\mathrm{v}}$ and $C_{\mathrm{c}}$. For this purpose, internationally established empirical relations are deployed (equations (10) and (11)) (Sanglerat 1972; CUR 1992; Lunne et al. 1997). The coefficients $\alpha_{\mathrm{m}}$ and $\beta_{\mathrm{c}}$ implemented in equations (10) and (11) to scale cone resistance depend on soil type, and for peat are $0.4-1.0$ and $0.8-1.6$ respectively.

In Figure 12, the above determined $m_{\mathrm{v}}$ is plotted against the net cone resistance values that correspond to the vertical effective stress intervals on which $m_{\mathrm{v}}$ was determined, using the function shown in Figure $9 \mathrm{~b}$ as input. The dashed line in Figure 12 indicates the interval in which $m_{\mathrm{v}}$ for peat predicted with CPT would fall when using the documented standard $\alpha_{\mathrm{m}}$ values. This zone plots below the $m_{\mathrm{v}}$ determined for this dataset. This discrepancy in $\alpha_{\mathrm{m}}$ values for Holocene peat in the Netherlands was also observed by Kruse (1998). Therefore, a value of 0.25 for $\alpha_{\mathrm{m}}$ was considered to better relate net cone resistance to $m_{\mathrm{v}}$ of peat (Fig. 12). The standard $\beta_{\mathrm{c}}$ coefficients also resulted in $C_{\mathrm{c}}$ values that are too low. These ranged between 0.7 and 1.4 and are representative for clay rather than peat (Mesri \& Ajlouni 2007). To obtain the $C_{\mathrm{c}}$ of 5.8 that corresponds to equation (5), a value of 6.3 was used for $\beta_{\mathrm{c}}$. When implementing the different organic matter classes, $m_{\mathrm{v}}$ and $C_{\mathrm{c}}$ are determinable using net cone resistance using equations (12) and (13):

$$
\begin{gathered}
m_{\mathrm{v}}=\frac{1}{\alpha_{\mathrm{m}} q_{\mathrm{n}}} \\
C_{c}=\frac{\left(1+e_{0}\right)\left(2.3 \beta \sigma^{\prime}\right)}{q_{n}} \\
m_{\mathrm{v}}=\frac{1}{(-0.43 N+0.61) q_{\mathrm{n}}} \\
C_{c}=\frac{\left(1+e_{0}\right)\left(2.3(2.8 N+1.3) \sigma^{\prime}\right)}{q_{n}}
\end{gathered}
$$

where $m_{\mathrm{v}}$ is the coefficient of volume compressibility $\left(\mathrm{kPa}^{-1}\right), q_{\mathrm{n}}$ is net cone resistance $(\mathrm{kPa}), \alpha_{\mathrm{m}}=0.25, C_{\mathrm{c}}$ is the compression index $(-), \sigma_{\mathrm{v}}^{\prime}$ is vertical effective stress at corresponding depth $(\mathrm{kPa}), e$ is void ratio at corresponding depth $(-), \beta_{\mathrm{c}}=6.3$ and $N$ is organic matter content $(-)$

\section{Discussion}

The results presented in this study show that CPT has the potential to be deployed for assessing primary compression of Holocene peat layers embedded in the coastal-deltaic plain of the Netherlands. Relations were found between the void ratio $(e)$ of peat and net cone resistance $\left(q_{\mathrm{n}}\right)$. Derived from this, the coefficient of volume compressibility $\left(m_{\mathrm{v}}\right)$ and the compression index $\left(C_{\mathrm{c}}\right)$ were (a)

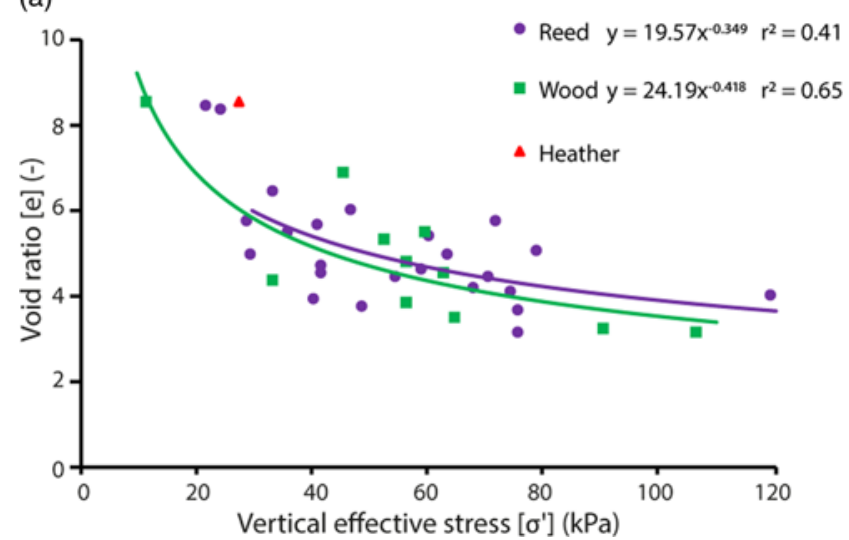

(b)

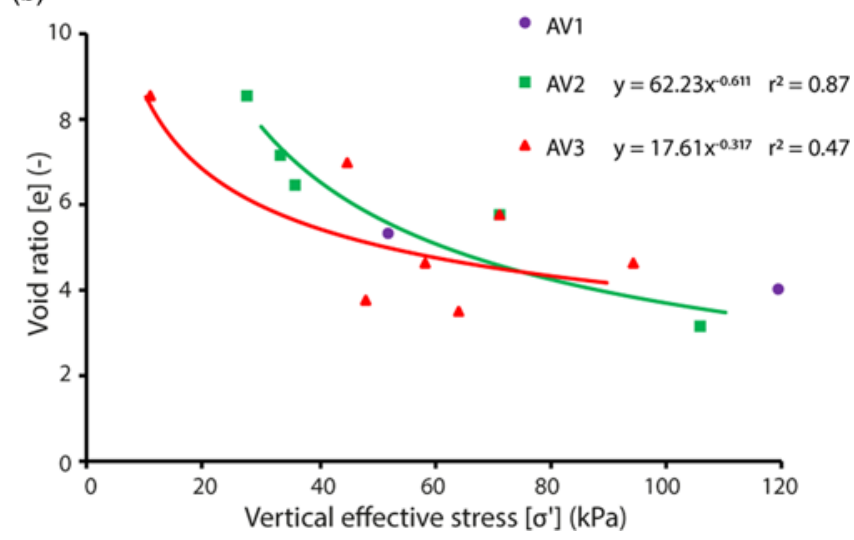

Fig. 8. Vertical effective stress-void ratio relations for (a) peat types and (b) different degrees of decomposition. 
CPT to characterize void ratio of Holocene peat
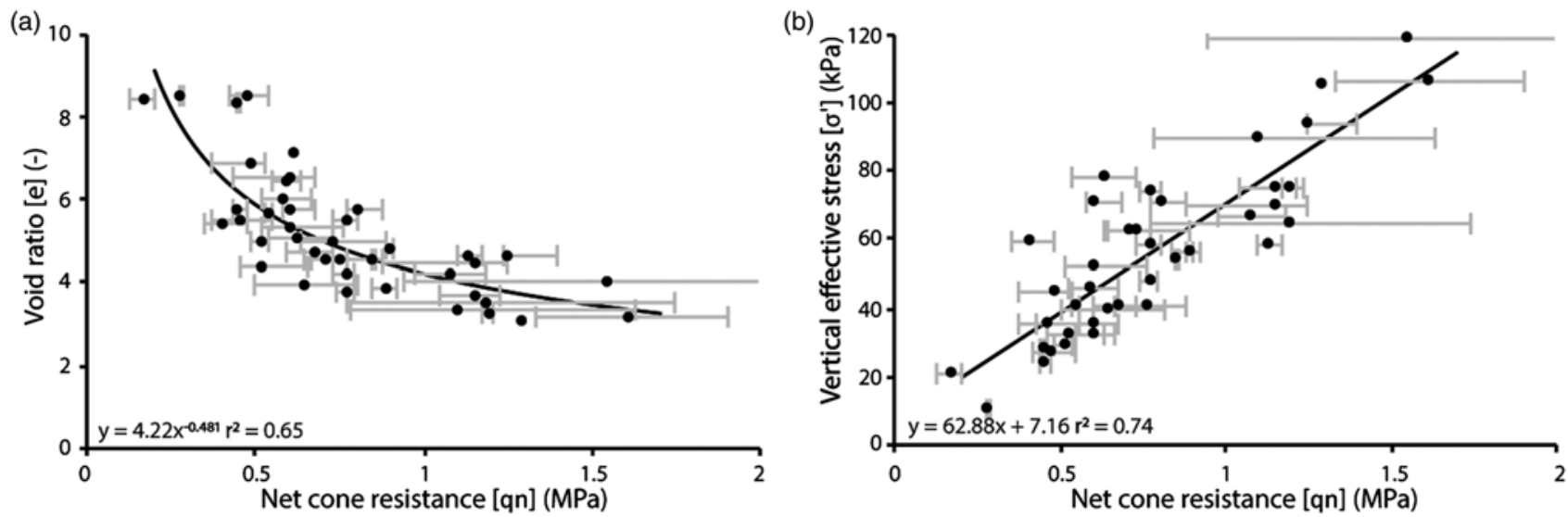

Fig. 9. Regression functions. (a) The measured void ratios for increasing net cone resistance. The error bars indicate the range of measured net cone resistance within a peat bed. (b) Vertical effective stress v. cone resistance.

quantifiable. Furthermore, relations were obtained between the amount of organic matter in peat, $q_{\mathrm{n}}$, and the derived $e, m_{\mathrm{v}}$ and $C_{\mathrm{c}}$ values. The void ratio of peat decreases with increasing admixed sediments, which reduces its compressibility and increases net cone resistance. For large spatial scale subsidence mapping, relating the organic matter content of peat to its compressibility is essential, as this peat property varies laterally and vertically in aggraded coastal- deltaic settings, and therefore causes differential subsidence when vertical effective stress increases (Nieuwenhuis \& Schokking 1997).

The application of CPT to determine compression of Holocene peat, in combination with the large quantities of available data stored in a national digital database, could make it a useful tool for mapping the potential for subsidence of the coastal-deltaic plain of the Netherlands by peat compression. However, before the CPTs

(a)

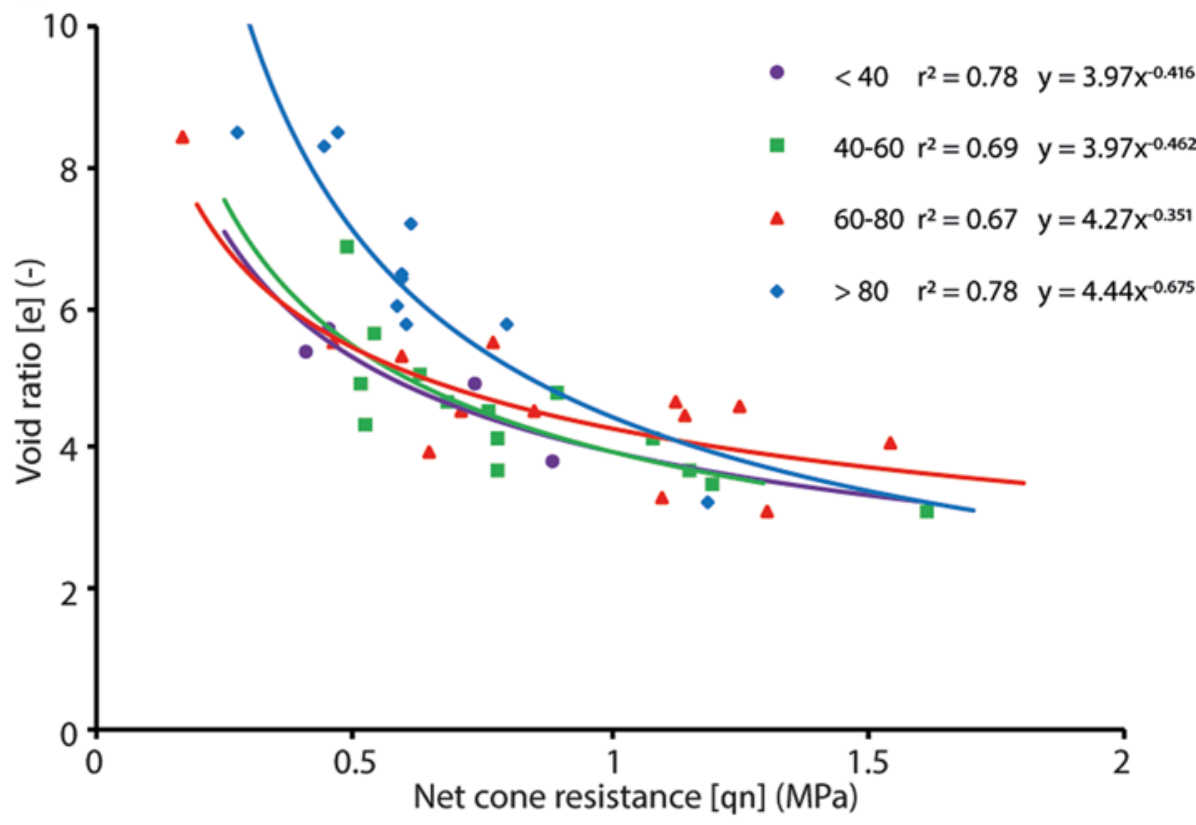

(b)
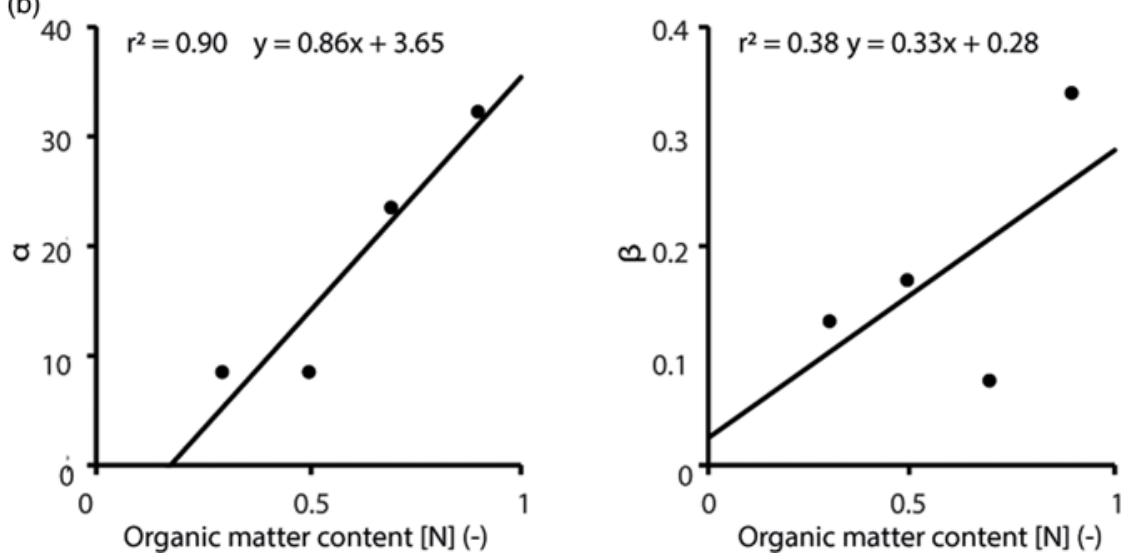

Fig. 10. (a) Overview of the different trend functions between net cone resistance and void ratio for different organic matter classes. (b) Linear relations between the $\alpha$ and $\beta$ parameters for different organic matter classes. 


\section{K. Koster et al.}

(a)

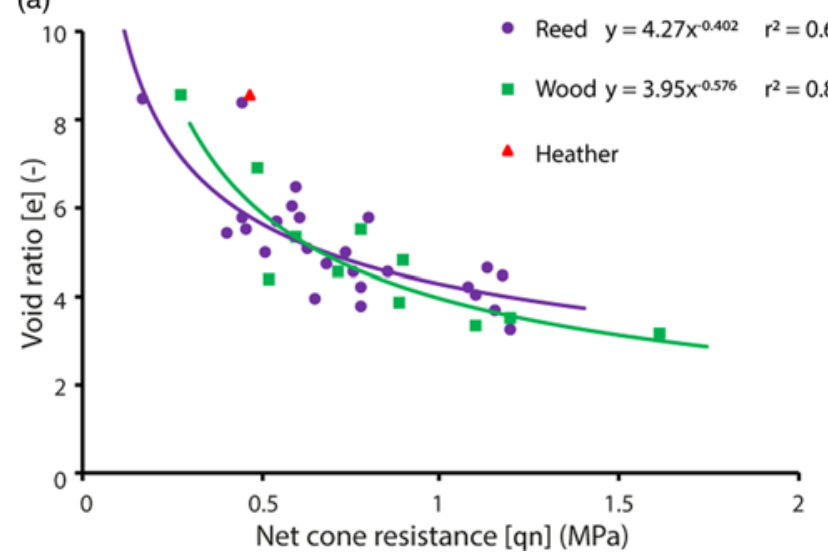

(b)

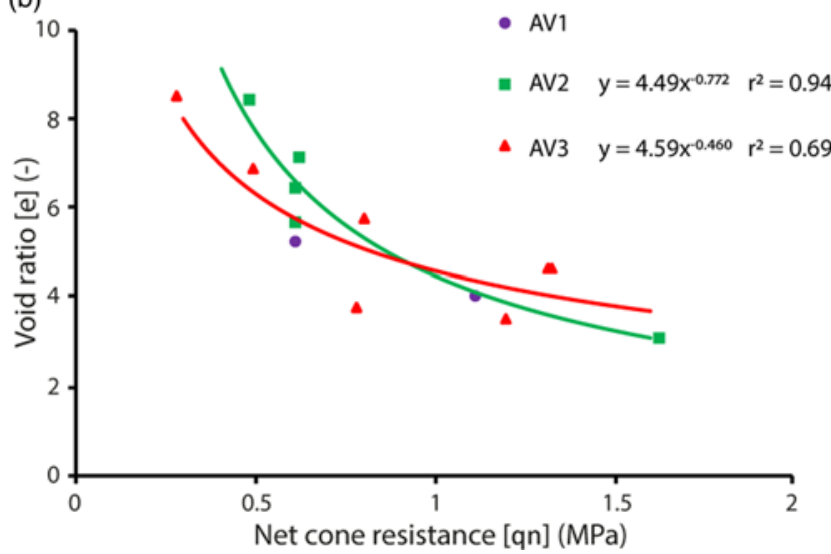

Fig. 11. Net cone resistance-void ratio relations for (a) peat types and (b) different degrees of decomposition.

stored in the national database are deployable, it is essential to validate the obtained empirical relations on larger datasets. This is essential, first, because more variation exists in the composition of peat embedded in the coastal-deltaic plain than represented in the dataset used here, regarding both vegetation type and admixed sediments (Bos et al. 2012). For instance, reed and wood peat are associated with wide ranges of admixed clastic sediments, owing to their spatially strongly varying proximity to sediment feeding sources, whereas sedge and moss peat are generally poor in sediments. Furthermore, the sediment fraction of peat formed intercalated within the Holocene sequences is often clay, whereas peat formed onlapping the Pleistocene substrate contains sand (Van de Plassche et al. 2010). In addition, mid- to late Holocene peat formed in the coastal plain has a higher organic matter content than coeval peat formed in the fluvial-dominated part of the delta (Bos et al. 2012). Also, regardless of vegetation type, peat beds situated near present-day artificial phreatic groundwater levels are more decomposed than deeper situated peat owing to seasonal fluctuations in groundwater tables (Nieuwenhuis \& Schokking 1997). Spatial variations in physical peat properties influence their compressibility, and consequently are essential for land subsidence studies. Therefore, further investigation of the relation between peat compression and net cone resistance is recommended, and should focus on peat embedded in different stratigraphical positions, situated in various proximities to phreatic groundwater levels, and composed of the major peat-forming vegetation, with broad ranges

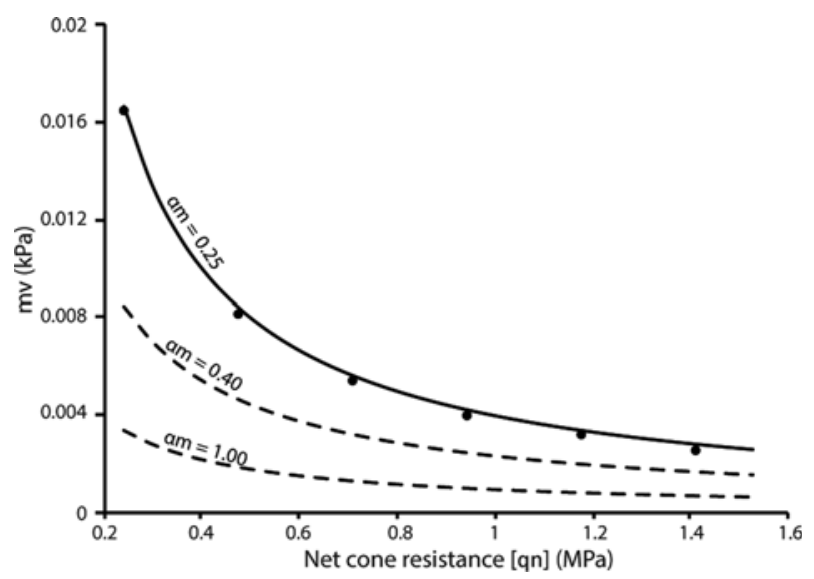

Fig. 12. Relation between net cone resistance and $m_{\mathrm{v}}$. The black dots indicate the $m_{\mathrm{v}}$ determined by vertical effective stress-void ratio relations; the continuous line indicates the $\alpha_{\mathrm{m}}$ proposed here; the dashed lines indicate previously proposed $\alpha_{\mathrm{m}}$ values typical for peat. in organic matter content with different sizes of admixed sediments. Future penetration testing should also focus on the influence of stems and branches incorporated in wood peat on measured resistances, as it is known that wood constituents yield much higher cone resistance values than a peat matrix (up to $8 \mathrm{MPa}$; Lunne et al. 1997). It is feasible that a part of the large TNO-GSN CPT database contains penetration tests that sounded woody material. Identifying such data is essential, because such high cone resistance values influence the characterized wood peat compressibility. Second, validation is essential because of the heterogeneity in data quality of the database. This is because the digital CPT data have been provided by different commercial parties during the last two decades. Although operational procedures of CPTs are standardized (ISO 2005), differences in cone type, pushing equipment and calibrations could have resulted in an inhomogeneous dataset of varying quality. Therefore, to determine the robustness of the results, the approach followed here should be reproduced with CPT data deriving from various parties. Furthermore, as peat compression is a still-continuing process, a maximum age of CPT data should be determined, as older CPT data do not well represent the current situation.

Peat compression is a combination of primary and secondary compression, which expresses thickness reduction by the expulsion of porewater under increasing effective stress, as well as by timedependent creep processes. Internationally, the most applied compression function using primary and secondary compression is that of Bjerrum (CUR 1992). The $m_{\mathrm{v}}$ and $C_{\mathrm{c}}$ of peat derived in this study are necessary for quantifying primary compression during a certain stress increase, and consequently serve as input for the Bjerrum function. However, secondary compression is important as well. Continuing secondary compression results in peat with a lower void ratio than expected based on in situ vertical effective stresses. This offset in void ratio is the overconsolidation ratio (OCR). In compression functions, the OCR is used to express primary compression as direct elastic or permanent, and to determine the equivalent age of the peat, which is used to determine creep rates when vertical effective stress is changed (Visschedijk 2010). For subsidence mapping in the Netherlands and elsewhere, it is therefore of utmost importance to also incorporate the OCR of peat in the mapping products. As the concept of OCR is important in soil mechanics in general, deriving it from CPT measurements has been the subject of multiple studies (e.g. Kulhawy \& Mayne 1990; Robertson 2009). These studies empirically relate cone resistance to OCR; however, they have not yet been calibrated for Holocene peat in the Netherlands. Therefore, during new CPT and coring campaigns, the preconsolidation stress of sampled peat layers should also be quantified prior to void ratio measurements. The 
Downloaded from http://qjegh.lyellcollection.org/ by guest on February 20, 2018

CPT to characterize void ratio of Holocene peat

resulting OCR of the peat can subsequently be related to cone resistance to parameterize existing $\mathrm{CPT}-\mathrm{OCR}$ functions for Holocene peat embedded in the subsurface of the coastal-deltaic plain of the Netherlands. This should improve the process of subsidence mapping using CPT.

\section{Conclusions}

In this study, it was shown that CPT data can be used as a proxy to estimate the in situ void ratio of peat layers embedded in the Holocene coastal plain of the Netherlands. This peat characteristic is essential to assess its degree of compression resulting from primary compression, and consequently its potential for further compression and land subsidence when effective stress is increased.

It was found that net cone resistance increases with decreasing void ratio, as organic fibres are progressively packed tighter together and interlock under increasing effective stress, thereby increasing the strength and stiffness of the peat layers. Furthermore, the organic matter content also influences the compressibility of peat, which was also derived from CPT measurements.

With the results presented here, in combination with the abundance of available data, CPT has the potential to become an important tool in mapping the subsidence potential of the coastaldeltaic plain of the Netherlands by peat compression. Prior to mapping, further validation using more extended peat and CPT datasets is necessary to better document the heterogeneous composition of Holocene peat, to improve relations between CPT and OCR, and to assess the quality of the large digital CPT database.

Acknowledgements We thank all our TNO-GSN colleagues involved in the gathering and processing of the CPT and cored borehole data for the TOPINTEGRAAL mapping programme. E. Stouthamer, G. Erkens, F. Busschers, J. Stafleu and K. Cohen are thanked for their input. We thank anonymous reviewers for their useful comments on earlier versions of the paper.

Funding This study was conducted as part of the $\mathrm{PhD}$ research of K.K., funded by TNO-GSN and Utrecht University.

Scientific editing by Cherith Moses; Jeffrey Keaton

\section{References}

Bos, I.J., Busschers, F.S. \& Hoek, W.Z. 2012. Organic-facies determination: a key for understanding facies distribution in the basal peat layer of the Holocene Rhine-Meuse delta, The Netherlands. Sedimentology, 59, 676-703, https:// doi.org/10.1111/j.1365-3091.2011.01271.x

Bosch, J.H.A. 2000. Standard borehole description protocol 5.1. TNO Geological Survey of the Netherlands, Report, 00-141-A [in Dutch].

Cheng-Hou, Z., Greeuw, G., Jekel, J. \& Rosenbrand, W. 1990. A new classification chart for soft soils using the piezocone test. Engineering Geology, 29, 31-47.

CUR. 1992. Construeren met grond. Civil Engineering Centre for Implementation Research and Regulation, Gouda, Report, 162 [in Dutch].

Den Haan, E.J. 1992. The formulation of virgin compression of soils. Géotechnique, 42, 465-483.

Den Haan, E.J. 1994. Vertical compression of soils. PhD dissertation, TU Delft.

Den Haan, E.J. \& Kruse, G.A.M. 2006. Characterisation and engineering properties of Dutch peats. In: Tan, T.S., Phoon, K.K. et al. (eds) Second International Workshop on Characterisation and Engineering Properties of Natural Soils, 3. Taylor \& Francis, Oxford, 2101-2133.

Drexler, J.Z., Fontaine, C.S. \& Deverel, S.J. 2009. The legacy of wetland drainage on the remaining peat in the Sacramento-San Joaquin delta, USA. Wetlands, 29, 372-386.

Erkens, G., Van der Meulen, M. \& Middelkoop, H. 2016. Double trouble: subsidence and $\mathrm{CO}_{2}$ respiration due to 1000 years of cultivation of the Dutch coastal peatlands. Hydrogeological Journal, 24, 551-568, https://doi.org/10. 1007/s10040-016-1380-4

Fokker, P.A., Gunnink, J., De Lange, G., Leeuwenburgh, O. \& Van der Veer, E.F. 2015. Compaction parameter estimation using surface movement data in Southern Flevoland. Proceedings of the IAHS, 372, 183-187, https://doi.org/ 10.5194/piahs-372-183-2015

Hijma, M.P., Cohen, K.M., Hoffmann, G., Van der Spek, A.F.J. \& Stouthamer, E. 2009. From river valley to estuary: the evolution of the Rhine mouth in the early to middle Holocene (western Netherlands, Rhine-Meuse delta). Netherlands Journal of Geosciences, 88, 13-53, https://doi.org/10.1017/ S0016774600000986

ISO 2005. Geotechnical investigation and testing - Field testing. Part 1: Electrical cone and piezocone penetration tests (ISO/DIS 22476-1:2005,IDT). International Organization for Standardization, Geneva.

Jorgensen, D.G. 1980. Relationships between basic soils-engineering equations and basic ground-water flow equations. US Geological Survey, Water Supply Papers, 2064

Koster, K., Erkens, G. \& Zwanenburg, C. 2016. A new soil mechanics approach to quantify and predict land subsidence by peat compression. Geophysical Research Letters, 43, 10792-10799, https://doi.org/101002/ 2016GL071116

Kruse, H. 1998. Deformation of a river dyke on soft soil. PhD dissertation, Utrecht University.

Kulhawy, F.H. \& Mayne, P.N. 1990. Manual on estimating soil properties for foundation design, Report EL-6800. Electric Power Research Institute, Palo Alto, CA.

Landva, A. 2006. Characterization of Escuminac peat and construction on peatland. In: Tan, T.S., Phoon, K.K. et al. (eds) Second International Workshop on Characterisation and Engineering Properties of Natural Soils, 3. Taylor \& Francis, Oxford, 2135-2192.

Long, M. \& Boylan, N. 2012. In-situ testing of peat - a review and update on recent developments. Geotechnical Engineering Journal of the SEAGS \& AGSSEA, 43, 41-55.

Lunne, T., Robertson, P.K. \& Powell, J.J.M. 1997. Cone penetration testing in geotechnical practice. Blackie, Glasgow; Spon/Routledge, New York.

Mesri, G. \& Ajlouni, M. 2007. Engineering properties of fibrous peats. Journal of Geotechnical and Geoenvironmental Engineering, 133, 850-866, https://doi. org/10.1016/(ASCE)1090-0241(2007)133:7(850)

Muntendam-Bos, A.G., Kleuskens, M.H.P., Bakr, M., De Lange, G. \& Fokker, P. A. 2009. Unraveling shallow causes of subsidence. Geophysical Research Letters, 36, 1-4, https://doi.org/10.1029/2009GL037190

NEN. 2001. NEN 5110. Geotechnics - determination of bulk mass density of soil in the laboratory - core cutter method Nederlands Normalisatie-Instituut, Delft [in Dutch].

Ngan-Tillard, D., Venmans, A. \& Slob, E. 2010. Total engineering geology approach applied to motorway construction and widening in the Netherlands. Engineering Geology, 114, 164-170, https://doi.org/10.1016/j.enggeo.2010. 04.013

Nieuwenhuis, H.S. \& Schokking, F. 1997. Land subsidence in drained peat areas of the Province of Friesland. Quarterly Journal of Engineering Geology, 30, 37-48, https://doi.org/0/1144/GSL.QJEGH.1997.030.P1.04

O'Kelly, B.C. \& Pichan, S.P. 2013. Effects of decomposition on the compressibility of fibrous peat - a review. Geomechanics and Geoengineering, 8, 286-296, https://doi.org/10.1080/17486025.2013.804210

Pons, L.J. 1992. Holocene peat formation in the lower parts of the Netherlands. Geobotany, 18, 7-80.

Robertson, P.K. 2009. Interpretation of cone penetration test - a unified approach. Canadian Geotechnical Journal, 46, 1337-1355, https://doi.org/101139/T09065

Sanglerat, M. 1972. Developments in Geotechnical Engineering, Vol. 1, The Penetrometer and Soil Exploration. Elsevier, Amsterdam.

Schothorst, C.J. 1977. Subsidence of low moor peat soils in the western Netherlands. Geoderma, 17, 265-291.

Serva, L. \& Brunamonte, F. 2007. Subsidence in the Pontina plain, Italy. Bulletin of Engineering Geology and the Environment, 66, 125-134, https://doi.org/ 10.1007/s10064-006-0057-y

TNO-GSN 2016. Online portal for data and information on the Dutch subsurface. TNO - Geological Survey of the Netherlands, https://www. dinoloket.nl/en

Törnqvist, T.E., Wallace, D.J. et al. 2008. Mississippi delta subsidence primarily cuased by compaction of Holocene strata. Nature Geoscience, 1, 173-176, https://doi.org/10.1038/ngeo129

Van Asselen, S. 2011. The contribution of peat compaction to total basin subsidence: implications for the provision of accommodation space in organic-rich deltas. Basin Research, 23, 239-255, https://doi.org/10.1111/j. 1365-2117.2010.00482.x

Van den Born, G.J., Kragt, F., Henkens, D., Rijken, B., Van Bemmel, B. \& Van der Sluis, S. 2016. Dalende bodem, stijgende kosten. PBL (Planbureau voor de Leefomgeving), Den Haag [in Dutch].

Van der Meulen, M.J., Van der Spek, A.J.F. et al. 2007. Regional sediment deficits in the Dutch lowlands: implications for long-term land-use options. Journal of Soils and Sediments, 7, 9-16, https://doi.org/10.1065/jss2006.12.1

Van de Plassche, O., Makaske, B., Hoek, W.Z., Konert, M. \& Van der Plicht, J. 2010. Mid-Holocene water-level changes in the lower Rhine-Meuse delta (western Netherlands): implications for the reconstruction of relative mean sea-level rise, palaeoriver-gradients and coastal evolution. Netherlands Journal of Geosciences, 89, 3-20.

Visschedijk, M. 2010. Isotachen berekening op een sigarendoosje. Geotechniek, 30-33 [in Dutch] 